\title{
Aspects of Orchid Conservation: Seed and Pollen Storage and their Value in Re-introduction Projects
}

\author{
Philip T. Seaton", Hugh W. Pritchard, Timothy R. Marks \\ Comparative Plant and Fungal Biology, Royal Botanic Gardens, UK
}

Copyright $(\mathcal{C} 2015$ by authors, all rights reserved. Authors agree that this article remains permanently open access under the terms of the Creative Commons Attribution License 4.0 International License

\begin{abstract}
Dry seeds of many orchid species, when stored at low temperatures, are capable of maintaining high levels of viability for many years, supporting orchid seed banking as a valuable part of emerging integrated conservation strategies. The Orchid Seed Science and Sustainable Use (OSSSU) network has already stored over 300+ species across 26 countries around the world. Its future ambition to store seeds representing a minimum of one thousand species in the next five years, and to expand the network to include more institutes and countries, provides an example of what can be achieved by a small dedicated group, willing to share their technical expertise and to develop a deeper understanding of the underlying science. Recent work indicates that it may also be possible to store orchid pollen of some species for a minimum of six years under similar conditions to those used for orchid seeds, thereby facilitating pollen exchange between collections. OSSSU partners in a number of countries have already demonstrated that raising plants from stored seeds can be used successfully in reintroduction projects.
\end{abstract}

Keywords Orchid, Seed, Pollen, Storage, Reintroduction, Research, Education

\section{Introduction}

With around 153 taxa (including some sub-species), Europe has an orchid flora roughly equivalent in numbers to North America excluding the sub-tropical state of Florida. Europe incorporates the Mediterranean Basin hotspot, an area that has been impacted by humans for millenia. According to Myers and Cowling [1] "the Mediterranean Basin is one of the hottest of hotspots; indeed in many ways it is hyper-hot, scoring very high in the fundamental criteria we use to define hotspots. It is exceptionally rich in diversity, especially plants, and second in the world in plant endemism. It is also highly threatened, and in fact has the lowest percentage of natural vegetation remaining in pristine condition of any hotspot".

According to the most recent IUCN Red List for Europe (www.iucnredlist.org/initiatives/europe) at first sight the current status of the continent's orchid species, however, may appear to present little cause for immediate concern. More than half the species are categorised as being of least concern. On the other hand, $62 \%$ of species are listed as decreasing, with the population status of a further $34 \%$ listed as being unknown. Many species remain subject to inappropriate land management and habitat change or the collection of tubers for salep, or of whole plants for horticulture. Thus 50 species (approximately one third of the total number of species) are listed as being either near-threatened or threatened. Of these 30 species (approximately one fifth of the total number of species) according to the Red List categories are either Vulnerable, Endangered or Critically Endangered. The future impact of climate change and a warmer world is a matter of great concern. Climate change predictions include warmer winters in Northern Europe and hotter and drier summers in the Mediterranean region, with an increase in the number of heat and drought events [2]. Orchids, with their reliance on specific symbiotic fungi at different stages in their life-cycles, specialized habitats and pollinators are particularly sensitive to environmental change and can be a key indicator of the overall health of the environment. They have been referred to as being potential "canaries in the coalmine" (www.serc.si.edu/labs/plant_ecology/naocc.aspx). A long-term population study has shown that Ophrys sphegodes in the south of England now flowers, on average, two weeks earlier than it did 32 years ago [3]. Climate change, combined with increasing habitat fragmentation, means that for many species natural migration of populations to suitable habitats may not be an option and a case may be made for future human-assisted translocations of populations to new habitats. In addition, small populations are often vulnerable to accidental loss. For example, 22 orchid species restricted to the mountain rainforest in the Montebello region of Mexico were lost when their habitat was completely destroyed by fire in an area where fire was used in the management of agricultural and cattle grazing [4]. 


\section{Orchid Seed Science and Sustainable Use (OSSSU)}

Seed banking has the potential to act as an insurance policy against possible future extinctions, preserving the maximum amount of genetic diversity in a minimum of space and at relatively little cost [5]. Indeed the extreme small size of individual seeds means that seed representing the whole of the European orchid flora could theoretically be stored in a small domestic freezer. A small number of such seed banks would provide a valuable resource for both horticulture and research, and maintain the possibility of future reintroductions. The value of such collections to the scientific community could be considerably enhanced if the percentage germination of full seeds was counted immediately post harvest and before the seeds were dried and stored at low temperature.

Orchid Seed Stores for Sustainable Use (OSSSU), a three year Darwin Initiative project funded by Defra the UK Department for Environment and Rural Affairs (http://darwin.defra.gov.uk/), was launched in the autumn of 2007 with workshops in Chengdu, China and at Jardín Botánico de Quito, Ecuador. A summary workshop was held in September 2010 at Jardín Botánico Lankester in Costa Rica bringing together representatives of each of the original participating institutes together with representatives of new recruits to the project. Initially focusing on fifteen countries in Asia (China, India, Indonesia, Philippines, Singapore, Thailand, Vietnam) and Latin America (Bolivia, Brazil, Chile, Colombia, Costa Rica, Cuba, Ecuador, Guatemala), the network has continued to expand to include at the time of writing additional countries in Asia (Laos, Nepal, India, Taiwan) and Latin America (Dominican Republic, Mexico, Panama, St Eustatius), the USA and a number of European partners (Estonia, Italy, Spain (Mallorca), Russia). Subsequent workshops have been held in Shenzhen, China, in April 2012, to stimulate the setting up of an in-country network, and in Jardín Botánico Orquideario Soroa, Cuba (October, 2012), for partners in Latin America.

The project was founded with the aim of setting up a global network of orchid seed banks using common protocols for drying and storing the seeds, and carrying out germination tests to measure both initial seed germination and subsequent changes in germination with time. The data gathered from this work would be made available to participants via the OSSSU web site (www.osssu.org). For each of the original 15 countries a target was set of storing seed of 20 species in a freezer at $-20^{\circ} \mathrm{C}$ per country over the three year period. The target was modest because of the work involved in carrying out regular germination tests on two different germination media. It was agreed that germination tests should be carried out on Knudson C [6], which would provide, for the first time, data enabling comparison of germination of a wide range of species from a wide range of countries and a wide range of habitats. At the same time seed was sown on what was deemed to be the 'best' medium available (i.e. the medium that was expected to result in the highest percentage germination for that particular species) to provide a comparison with results obtained with Knudson C. The original target of 300 species stored was exceeded by a considerable margin by the end of the three year period, and the number of seed lots stored continues to increase as the network expands to include more countries and institutes [7].

Key to the success of the project was obtaining good quality seed at the outset. This can be defined as being seed that has reached full maturity and is free from contamination by bacterial and fungal spores together with a high level of full seeds and initial percentage germination. The importance of collecting mature seed cannot be over-emphasised. Although it is possible, or even routine, to sow immature seeds of many species, commercially to obtain seedlings for sale more quickly or to overcome problems of dormancy of mature seeds (e.g. many Cypripedium species), immature seeds will not tolerate drying and therefore it is not possible to store them in seed banks. Although wild-collected seed was stored where cultivated material was not available (e.g. Chile), for practical reasons (collecting seed in the wild can be expensive and time-consuming) the majority of seed collections were made with hand-pollinations in living collections. Charles Darwin [8] was fascinated by the often bizarre pollination mechanisms of orchids that in many cases are by no means obvious to the casual observer. Thus teaching horticulturalists and students about the intricacies of orchid flower structure forms an integral part of orchid seed banking activities. Cross-pollination should be the norm, thereby capturing the maximum amount of genetic variation within a species. It also avoids the problems of self-incompatibility that have been shown to occur in a number of orchid genera such as Oncidium and Restrepia [9].

Correct identification of the species is vital. To allow future conservationists to confirm an identification it is desirable that herbarium vouchers are taken where practical (i.e. material should only be removed if it is not going to have a detrimental impact on the orchid population being sampled). The genus Ophrys has, for example, been the subject of much debate as to what constitutes a true species [10] and well-documented reference material may be invaluable in future. In any case, the plant should be photographed when in flower, showing close-up details of the flowers, the whole plant and, where seed is collected in its natural habitat, the habitat and any further relevant details (exact location, co-flowering species, aspect etc.).

In the initial stages of the project two people from each participating institute were trained, thereby minimising the risk to the project of loss of expertise through unpredictable staff turnover. It was expected that the skills would then be passed on to other members of that institute through cascade training and many of the participating institutes have their own training programmes. For example, a number of five-day workshops have taken place in Ecuador at Jardín Botánico Quito where students have been instructed in seed storage techniques beginning with pollination and through to 
measuring percentage germination. Indeed regular and effective communication and continuous training are essential to the continued success of the project.

Many orchids are relatively easy to grow from seed using equipment that can be found in the average kitchen [11]. A description of the recommended techniques is available in Growing Orchids from Seed [12], and its subsequent publication in Spanish through the auspices of OSSSU [13] has made the techniques described available to orchid biologists in Spain and Latin America. It is also due to be published in Chinese in 2015 through Kunming Institute of Botany (Chinese Academy of Science). The vast majority of epiphytic orchids can be germinated successfully in the laboratory asymbiotically, and although this is also true for many European terrestrial orchids [14], many species germinate more rapidly and produce more robust plants when germinated using an appropriate symbiotic fungus [15]. Thus it is often desirable, and sometimes essential, to isolate suitable symbiotic fungi [16]. Isolation techniques, including seed baiting, are widely employed and fungal isolates can be stored at low temperatures [14].

\section{OSSSU: Future Activities}

A decision was recently made to change the name (but not the initials) of the project to Orchid Seed Science and Sustainable Use to better reflect its future aims in focusing on science. The work taking place at the Universidade do Oeste Paulista (UNOESTE), Brazil, provides an example of what can be achieved. Teaching is a core function of the project at UNOESTE. Students are taught about the floral biology and pollination techniques for both large flowering Cattleya and the small flowered Pleurothallis. Seed biology, seed storage and germination protocols are studied. As stated above, it is highly desirable to have a high value for initial viability. This can be measured using germination tests on sterile media but there is increasing interest in using vital stains such as fluoroscein diacetate or tri-phenyl tetrazolium chloride. Such stains, where they are closely correlated with germination tests, have the potential to make assessments of viability quicker and easier to carry out. Thus Hosomi et al. $[17,18]$ have used the tetrazolium stain to determine seed viability, capturing images using a digital camera to enable a permanent record of observations to be made.

To date limited work has been carried out on orchid pollen storage. However, evidence gathered at Kew's Millennium Seed Bank has shown that pollen; conveniently stored as intact pollinia, has similar longevity kinetics to seed and may be stored for several years and successfully used to sire new seeds, if dried to a suitable moisture content and stored at $-20^{\circ} \mathrm{C}$ [19]. Although $-196^{\circ} \mathrm{C}$ may also be suitable [20]. This raises the possibility of collaborations between institutes holding living collections either in the same country, or between countries where exchange of pollen would ensure the maintenance of genetic diversity within populations, and support out of season pollination of exotic species.

\section{Reintroductions and Community Involvement}

A number of successful orchid re-introduction projects have been and are being undertaken throughout the world with both epiphytic and terrestrial species. Such projects take commitment and time. Some are focused on botanical gardens and some on university departments. Others are carried out by groups of enthusiastic amateurs. Successful reintroductions of epiphytes include that of Cyrtopodium punctatum in the Fakahatchee Strand in Florida by staff from Atlanta Botanical Gardens and the Florida State Parks Department [21]. A total of 16 species have been reintroduced by scientists at the National Botanical Gardens in Singapore over the past ten years, most notably what is reputed to be the world's largest orchid, Grammatophyllum speciosum [22]. Cattleya quadricolor is being propagated for reintroduction in Cali, Colombia by members of la Sociedad Vallecaucana de Orquideología [23]. The flagship for successful reintroduction of a terrestrials orchid in the UK has been Cypripedim calceolus which, due to wild collection, had been reduced to a single plant in its native habitat [14]. Other examples of reintroduction projects with terrestrial species include Cypripedium kentuckiense and Platanthera chapmannii in Georgia USA (Richards pers. comm.) (http://www.atlantabotanicalgarden.org/conservation/tissueculture-lab); Platanthera leucochila by orchid biotechnologists at Illinois College, USA (http://www.ic.edu/orchidrecoveryprogram); Diurus fragrantissima in Eastern Austalia [24]; Cypripedium macranthos in China [25] and one of North America's rarest orchids, Peristylus holochila, in Hawaii [26].

Most of the above projects are dependent on small numbers of committed individuals working for little or no financial reward. Such volunteers frequently bring with them a different set of skills to those scientists who are co-ordinating the projects. Without such community involvement many of the projects would fail. The comments of two scientists running such community projects in Eastern Australia and Tasmania are apt. Noushka Reiter [pers. comm.] writes from Eastern Australia that in the last two years she has introduced about ten species with colleagues and community groups and she is looking at another 17 to 20 to re-introduce over the next two years. She writes, "To be honest if we didn't have the community groups and cross agency support to help in all aspects of the program we would have folded years ago". Likewise Nigel Swartz [pers. comm.] in Tasmania says, "My volunteers are wonderful, with many coming with a complete skill set in sterile technique with long backgrounds in science and research - they were just so desperate to work with orchid fungi!"

To be effective, future successful conservation activities should expand to develop educational programmes and 
involve the participation of a wider range of stake-holders, bringing with them a broad range of experience and expertise, and willing to work on various aspects of orchid conservation in what is becoming known as 'Citizen Science'. In the UK this is beginning through the National Collections (organised by the charity Plant Heritage) of different orchid genera held by dedicated amateur growers who are following the OSSSU protocols [27]. Successful germination of orchid seeds (often on Petri dishes) inevitably leads to protocorms that can be transferred to larger culture vessels, and perhaps different culture media, for 'growing on' until they are sufficiently large to be transplanted into a suitable medium or compost. Such plants can and are being used by OSSSU partners to enhance living collections thereby reducing collection pressures on wild populations and for possible reintroductions. Terrestrial orchids can be planted in raised beds (Richards, pers. comm.) or, where appropriate, artificial bogs or marshes [28] where they can be grown until they are large enough to be transferred to reintroduction sites.

\section{Education}

IUCN recommendations include raising public awareness. If we are to convince the general public of the importance of conservation we need to engage with as wide an audience as possible, thus OSSSU partners continue to be involved in public outreach through giving talks at local societies and presentations at conferences. Growing orchids from seed provides an ideal entry into conservation activities both for adults and children. OSSSU partners in Cuba and the Dominican Republic have active outreach programmes for schoolchildren. King Charles $1^{\text {st }}$ School in Kidderminster and Writhlington School in Radstock in the UK have dedicated and well-resourced orchid laboratories providing an opportunity to introduce and focus the enthusiasm of a younger generation on the importance of orchid conservation. Where examination syllabuses in biology are focusing increasingly on molecular biology and the teaching of plant biology is increasingly marginalised, they provide an opportunity for students to learn about the importance of plants and their conservation and participate in practical conservation activities [29].

\section{European Orchids and OSSSU}

The advantages of belonging to the OSSSU network include an opportunity to exchange information and advice. OSSSU currently has four partner countries within Europe (Estonia, Italy, Spain and Russia) working on their regional orchid floras and there are opportunities to involve additional institutes and countries in the network. There is currently a movement to establish a North American Orchid Conservation Center (NAOCC) and one wonders if it would not be possible to establish a similar network within
OSSSU for European countries. An initial target for such a network could be to have representative seed of all native orchids under long-term seed bank conditions by 2020, a target similar to that set for the orchids of southwest Australia biodiversity hotspot with 408 native terrestrial orchid species [30].

\section{Conclusions}

It seems apt to conclude with the aphorism 'there is no time like the present'. In other words we should begin storing seed and pollen without delay. However, to ensure this is successful and provides a suitable and sustainable genetic resource for the future, there are several key aspects to be developed.

- Species at immediate risk of extirpation must be established as living collections in botanical gardens, or other appropriate locations, to conserve both germplasm, and to provide an educational resource to a broad range of orchid conservationists.

- As orchids possess high commercial value in terms of their horticultural, medicinal and culinary usages, greater collaboration in regard to germplasm storage and reproduction with these sectors would reduce the pressure on collection from wild populations.

- In addition to the use of seed, the role of vegetative reproduction; naturally practiced by many species in the wild, should be further developed for use by commercial sectors, and where appropriate, also for conservation.

- There is a critical need to understand the processes involved in pollination to obtain good seed set, and the role and ecology of natural pollinators; essential to maintaining a healthy natural population.

- Equally, the role and storage of natural fungal symbionts needs to be understood, and these need to be co-stored with seed in order to provide the most suitable propagules for re-introduction.

- Seeds of terrestrial species can express various levels of dormancy (e.g. Cephalanthera longifolia), and research is required to understand both natural mechanisms and how these may be affected by seed storage at low temperature.

- Success have been achieved in storing seeds and pollen at $-20^{\circ} \mathrm{C}$, but much more research is required to understand the relationship between temperature and moisture content upon longevity across a broader range of species, and especially the use of ultralow $\left(-196^{\circ} \mathrm{C}\right)$ temperatures achieved in liquid nitrogen.

- This information, expertise in seed and pollen conservation, and the germplasm itself, need to be disseminated internationally. Such a mechanism is developing through the OSSSU network, facilitating knowledge sharing and potential collaboration through its website (www.osssu.org). 
The fate of natural orchid populations provides a 'canary in the coalmine' assessment of whole habitat status to help direct conservation strategies, but appreciation of their part in creating a beautiful natural world should also not be lost.

\section{REFERENCES}

[1] N. Myers, R.M. Cowling. Mediterranean Basin, In: R.A. Mittermeier, N. Myers, P.R. Gil, C.G. Mittermeier (eds), Hotspots, CEMEX S.A. pp. 255-265, 1999.

[2] F. Giorgi, P. Lionello, Climate change projections for the Mediterranean region, Global and Planetary Change, Vol. 63, 90-104, 2009

[3] M.J. Hutchings. The population biology of the early spider orchid Ophrys sphegodes Mill. III. Demography over three decades. Journal of Ecology, Vol. 98: 867-878, 2010.

[4] M.A. Soto Arenas, R. Solano Gomez, E. Hagsater. Risk of extinction and patterns of diversity loss in Mexican orchids. Lankesteriana, Vol. 7: 114-121, 2007.

[5] P.T. Seaton, H.W. Pritchard. Orchid Germplasm Collection, Storage and Exchange. In: K.W. Dixon, S.P. Kell, R.L. Barrett, R.L. and P.J. Cribb (eds.) Orchid Conservation. Natural History Publications (Borneo), Kota Kinabalu, pp 227-258, 2003.

[6] L. Knudson. A new nutrient solution for orchid seed germination. American Orchid Society Bulletin, Vol. 15: 214-217, 1946.

[7] P.T. Seaton, H. Hu, H. Perner, H.W. Pritchard. Ex situ Conservation of Orchids in a Warming World. Botanical Review, Vol. 72: 193-203, 2010.

[8] C. Darwin. The various contrivances by which orchid are fertilised by insects. $2^{\text {nd }}$ ed. John Murray, London, 1899.

[9] H.J. Millner, A.R. McCrea, T.C. Baldwin. The use of ex situ orchid collections in conservation research with reference to Restrepia (Orchidaceae). Proceedings of the $20^{\text {th }}$ World Orchid Conference, 2011, Singapore, 2012.

[10] H.A. Pedersen, N. Faurholdt. Ophrys the bee orchids of Europe. Royal Botanic Gardens Kew, 297 pp, 2007.

[11] P.T. Seaton, H.W. Pritchard. Life in the freezer. Orchids, Vol. 76:762-773, 2008.

[12] P.T. Seaton, M. Ramsay. Growing Orchids from Seed. Royal Botanic Gardens Kew, 83 pp, 2005.

[13] P.T Seaton, M. Ramsay, J. Warner. Cultivo de orquídeas por semillas. Royal Botanic Gardens Kew, 82 pp, 2009.

[14] M.M. Ramsay, K.W. Dixon. Propagation science, recovery and translocation of terrestrial orchids. Pp. 227-258 in K.W. Dixon, S.P. Kell, R.L. Barrett, R.L. and P.J. Cribb(eds.) Orchid Conservation. Natural History Publications (Borneo),
Kota Kinabalu. pp. 259-288, 2003.

[15] P.T. Seaton, P. Cribb, M. Ramsay, J. Haggar. Growing Hardy Orchids. Royal Botanic gardens Kew, 128 pp, 2011.

[16] H.N. Rasmussen. Terrestrial orchids from seed to mycotrophic plant. Cambridge University Press, Cambridge, 1995.

[17] S.T. Hosomi, R.B. Santos, C.C. Custódio, P.T. Seaton, T.R. Marks, N.B. Machado-Neto. Preconditioning Cattleya seeds to improve the efficacy of the tetrazolium test for viability. Seed Science and Technology Vol. 39: 178-189, 2011.

[18] S.T. Hosomi, C.C. Custódio, P.T. Seaton, T.R. Marks, N.B. Machado-Neto. Improved assessment of viability and germination of Cattleya (Orchidaceae) seeds following storage. In Vitro Cellular and Developmental Biology - Plant, Vol. 48: 127-136, 2012.

[19] T.R. Marks, P.T. Seaton, H.W. Pritchard. Desiccation tolerance, longevity and seed-siring ability of entomophilous pollen from UK native orchid species. Annals of Botany, Vol. 114, 561-569, 2014.

[20] H.W. Pritchard, F.G. Prendergast. Factors influencing the germination and storage characteristics of orchid pollen. In: Modern Methods in Orchid Conservation: The Role of Physiology, Ecology and Management. H.W. Pritchard H.W. (ed.), Cambridge University Press, UK, 1-16, 1989.

[21] D. Ferreira, M. Richards, P.T. Seaton. Saving Florida's Cigar Orchid. The Orchid Review, Vol. 120: 158-161, 2012.

[22] T.W. Yam. Native Orchids of Singapore: Diversity, Identification and Conservation. ISBN-978-981-07-8078-4, $122 \mathrm{pp}, 2013$

[23] P.T. Seaton, J.E. Orejuela Gartner. Saving Cattleya quadricolor. Orchids, Vol. 548-551, 2009.

[24] P.T. Seaton, Orchids in Peril. The Orchid Review, Vol. 117:82-84, 2009

[25] P.T. Seaton. Conserving Cypripedium macranthos. The Orchid Review, Vol. 118: 42-45, 2010.

[26] L.W. Zettler, S.P. Perlman. (2012) Hawaii's rarest native orchid and the battle to save it from extinction. Orchids, Vol. 81:94-99, 2012.

[27] P.T. Seaton. Ten years of Maxillaria Magic. Plant Heritage NCH, Autumn 2011 pp. 2-5, 2011.

[28] G. Londo. Creating habitats for some marsh orchid species in nature gardens. The Orchid Review, Vol. 100: 339-343, 1992.

[29] P.T. Seaton, J.P. Kendon, H.W. Pritchard, D.M. Puspitaningtyas, T.R. Marks. Orchid conservation: the next ten years. Lankesteriana, Vol. 13: 93-101, 2013.

[30] N.D. Swartz, K.W. Dixon. Perspectives on orchid conservation in botanic gardens Trends in Plant Science 14:590-598, 2009. 